GEOLOGICAL SURVEY CIRCULAR 540

\title{
A Simple Mercury Vapor Detector for Geochemical Prospecting
}

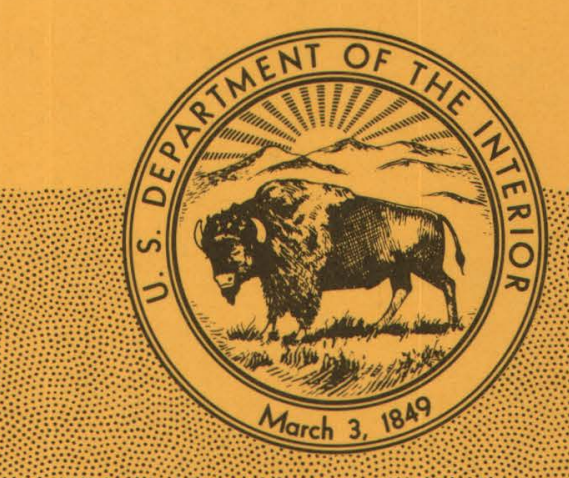




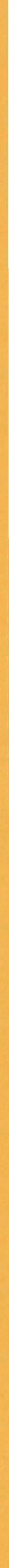




\section{A Simple Mercury Vapor Detector for Geochemical Prospecting}

By W. W. Vaughn

GEOLOGICAL SURVEY CIRCULAR 540

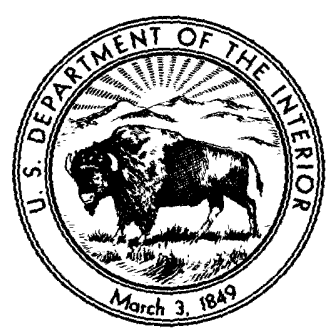




\section{United States Department of the Interior}

ROGERS C. B. MORTON, Secretary

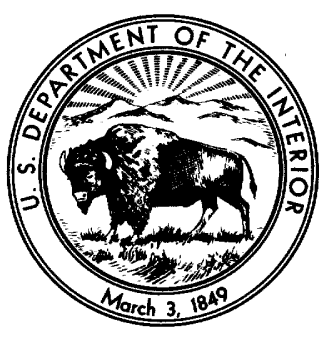

\section{Geological Survey}

William T. Pecora, Director

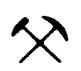

First printing 1967

Second printing 1968

Third printing 1971

Free on application to the U.S. Geological Survey, Washington, D.C. 20242 


\section{CONTENTS}

Page Page

Abstract -

1 Instrument design (electronic) -

Introduction -

1 Instrument operation - 6

General description -

Calibration -....... 6

1 References- 8

\section{ILLUSTRATIONS}

Figure 1. Photograph of mercury vapor detector

2. Functional diagram of mercury vapor detector -

3. Photograph of amalgamative mercury-extraction stage (thermoamalgamator) -

4. Circuit diagram of mercury vapor detector

5. Circuit diagram of power supply

6. Temperature-saturation curve for mercury vapor in air

\section{PARTS LIST}

$R_{1} \quad$ Clarostat series 51 high-voltage potentiometer, 5 megohms, CM 33507

$\mathrm{R}_{2}$ Clarostat series 62JA 10-turn potentiometer, 100,000 ohms

$\mathrm{R}_{3} \quad$ Resistor, 500,000 ohms, $1 / 4$ watt

Resistor, 250,000 ohms, $1 / 4$ watt

Ohmite potentiometer type $2541,250,000 \mathrm{ohms}$

Same as $\mathbf{R}_{5}$

Resistor, 50,000 ohms, $/ 4$ watt

Same as $\mathrm{R}_{7}$

Resistor, 8,000 ohms, 2 watts

Ohmite potentiometer type $1041,100,000 \mathrm{ohms}$

Amphenol potentiometer type 994P trimmers; 200 ohms
$\mathrm{R}_{12}$ Amphenol potentiometer type 994P trimmers, 1,000 ohms

$\mathrm{R}_{13}$ Amphenol potentiometer type 994P trimmers, 2,000 ohms

$\mathrm{R}_{14}$ Amphenol potentiometer type 994P triminers, 5,000 ohms

$\mathrm{R}_{15}$ Ohmite potentiometer model E, type 0122, 3,500 ohms, 10 watts

$\mathrm{R}_{16}$ Resistor, 1,500 ohms, 10 watts

$\mathrm{R}_{17}$ Resistor, 20,000 ohms, 10 watts

$V_{1}, V_{2} 6201$ twin-triode vacuum tube

M1 10-microampere taut band meter

$P_{1} \quad$ RCA 935 photocell 



\title{
A Simple Mercury Vapor Detector for Geochemical Prospecting
}

\author{
By W. W. Vaughn
}

\begin{abstract}
The detector utilizes a large-volume atomic-absorption technique for quantitative determinations of mercury vapor thermally released from crushed rock. A quartz-enclosed noble-metal amalgamative stage, which is temperature controlled and is actuated by a radio-frequency induction heater, selectively traps the mercury and eliminates low-level contamination. As little as 1 part per billion of mercury can be detected in a 1 -gram sample in a 1 -minute analytical period.
\end{abstract}

\section{INTRODUCTION}

Although the geochemistry of mercury and its geologic environmental behavior as a free element are not fully understood, mercury is recognized to be an indicator element for mineral deposits and, in certain geologic surroundings, for some heavy metals in direct association with it (Saukov, 1946; Hawkes and Williston, 1962; Williston, 1964; Williston and Morris, 1965; Erickson and others, 1964, 1966; Friedrich and Hawkes, 1966). Of the procedures available for mercury determinations, the large-volume low-temperature atomic-absorption technique seems to be the most practical for geochemical studies. The sensitivity and reliability of this technique have been demonstrated (Vaughn and McCarthy, 1964). The minimal version of the apparatus described here will be helpful to most people who are interested in determining the mercury content of materials occurring naturally.

\section{GENERAL DESCRIPTION}

A single-beam atomic-absorption mercury vapor detector with a needle-type meter indicator has been developed for rapid and accurate mercury analysis. The primary objective was to build a very simple and portable instrument for vehicular operation that would meet the requirements for extensive geochemical investigations in the field. The system (fig. 1) consists of a two-stage quartz-enclosed thermoamalgamator (a) operated by a radio-frequency induction heater (b) an absorption chamber (c) with a constant-temperature ultraviolet light source, and a balanced bridge differential amplifier (d). Normaily the instrument, which has a sensitivity of 1 part per billion in a 1-minute analytical period, requires a 0.25 -gram rock sample crushed to 80 -mesh size. The sample, upon being heated to approximately $500^{\circ} \mathrm{C}$, releases mercury as a vapor. The mercury vapor is carried up the quartz tube by an airstream and selectively trapped by amalgamation with silver while contaminants pass through. The mercury is then thermally released from the amalgam into the absorption chamber and measured quantitatively. The instrument response is calibrated in parts per billion using a known volume of saturated mercury vapor. A T-valve allows the airstream to be directed through the chamber or diverted to bypass the chamber.

A functional diagram of the detector is shown in figure 2. Mercury vapor and other volatile materials (a) from the heated rock sample (b) are drawn into an upright quartz tube (c) where the separation and amalgamation take place. Dust and, to some extent, chemical contaminants are arrested by the lead-acetateimpregnated glass-wool filter plug (d). The mercury vapor from the airstream is extracted by the silver mercury trap (e), and contaminating substances (smoke, particulate matter) are shunted through the bypass (f). The trap is then heated to $500^{\circ} \mathrm{C}$, in approximately 7 seconds, and the mercury vapor is released through the absorption chamber. The unexcited atoms in the mercury vapor attenuate the light beam from the ultraviolet lamp ( $\mathrm{g}$ ), which reduces the current in the photocell (h) $)$. This simultaneous action produces a meter reading at the amplifier proportional to the mercury concentration in the chamber. The mercury vapor and airstream are moved through the "gas train" in the instrument at a flow rate of 2,000 cubic centimeters per minute. Maximum absorption and peak meter reading are usually reached in about 5 seconds.

\section{INSTRUMENT DESIGN (PHYSICAL)}

The amalgamative mercury-extraction stage, here called a thermoamalgamator, is built on a standard laboratory-type double-pole double-throw knife-blade switch on a bakelite base (fig. 3). A 3/4-inch hole to receive the quartz tube is drilled through the body of the switch parallel to the long axis and is located so that the detent positioning system is retained. Soft copper tubing, having $1 / 8$-inch OD (outside diameter) and 0.030 -inch wall thickness, is wound to form the radio-frequency induction heating coils, which have a 


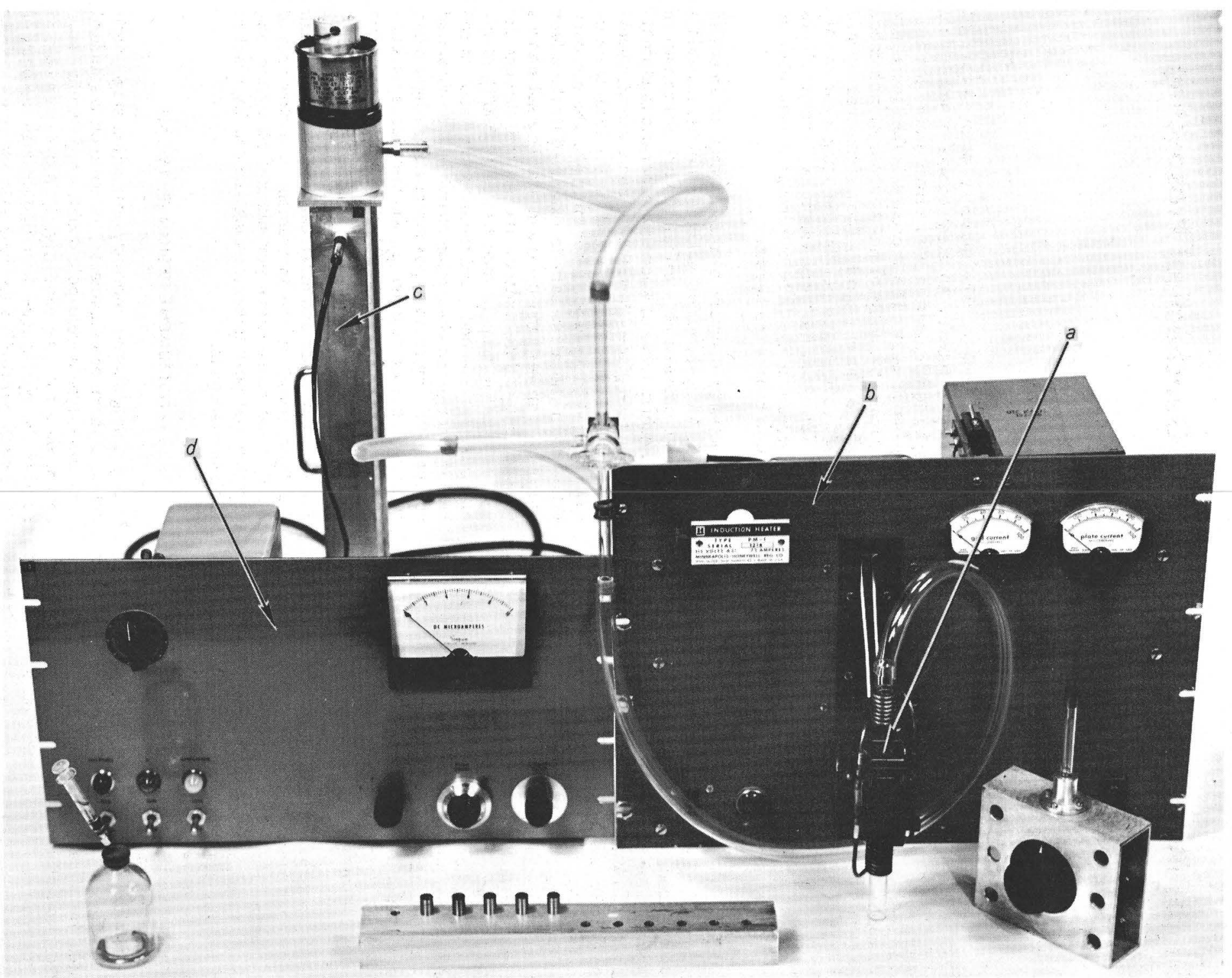

Figure 1.-Mercury vapor detector, including noble-metal amalgamator (a), radio-frequency induction heater (b) , absorption chamber (c), and differential amplifier (d). 


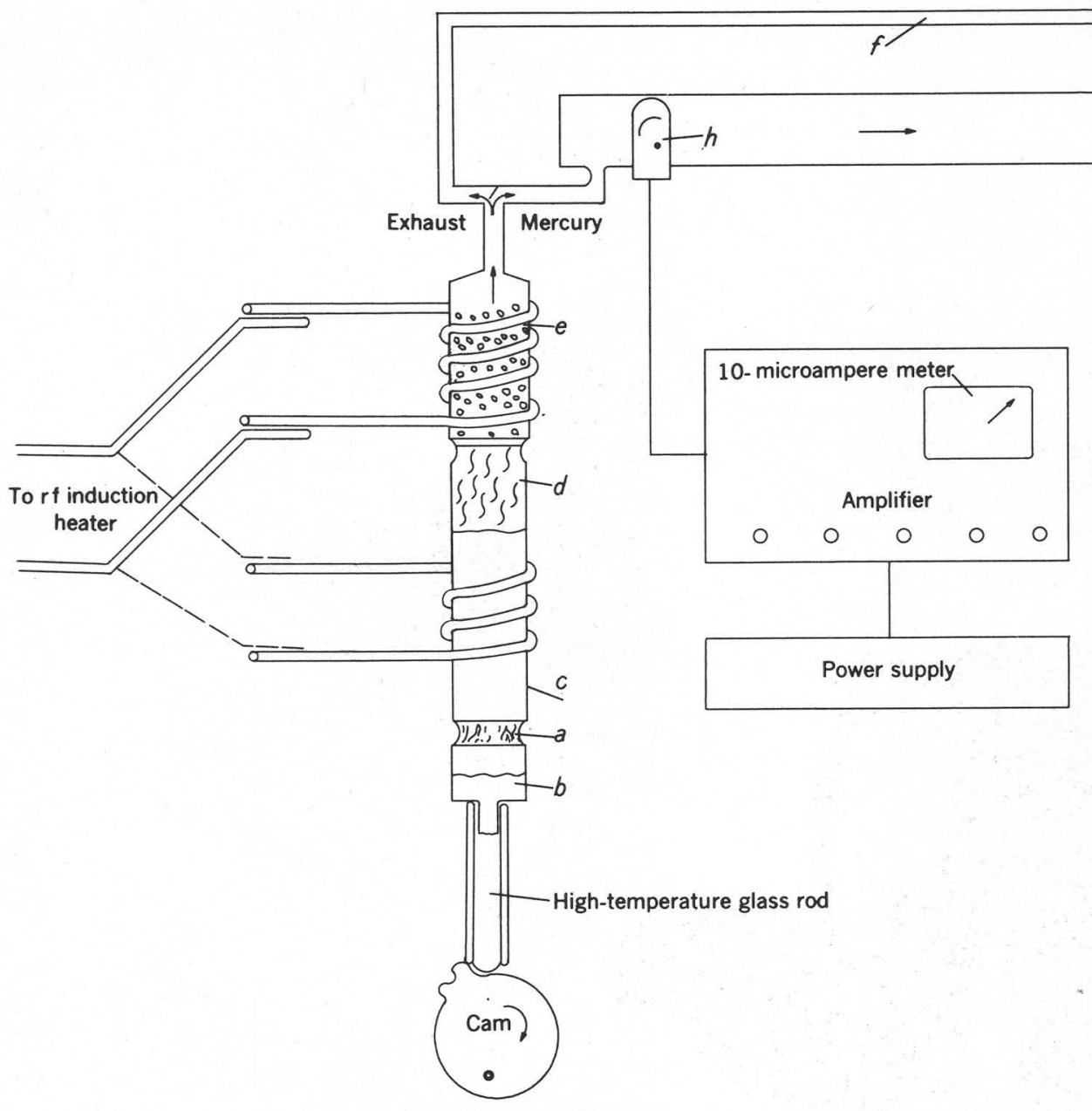

Figure 2.-Functional diagram of mercury vapor detector, including mercury vapor and other volatile materials (a), heated rock sample (b), upright quartz table (c), glass wool filter plug impregnated with lead acetate $(\underline{d})$, silver mercury trap $(\underline{e})$, bypass (f), ultraviolet lamp (g), and photocell (h) . rf, radio frequency.

$5 / 8$-inch inside diameter with seven full turns spaced 0.015 inch apart. The coils are connected to the terminal posts at the ends of the switch with a No. 2 Exacto wire clamp. The coils serve to c oncentrate the radio-frequency electromagnetic radiation in a pattern experimentally determined to be optimum for this heating application. The common switch terminals are connected to the output terminals of a 0.5 -megacycle 750-watt induction heater with $1 / 4$-inch-square bus bars sawed from a 2 -inch aluminum L-beam. The ends of the copper tubing extend one-half an inch past the clamp so that flexible plastic tubing may be attached for the cooling system. Water is circulated through the coils at a rate of 1 quart per hour.

The quartz tube $(228 \mathrm{~mm}$ long by $15-\mathrm{mm}$ OD by 1-mm wall thickness) containing the mercury trap and filter plug may be inserted after the axes of the copper-tube coils and the hole through the switch have been alined to allow 0.002 -inch radial clearance between the tube and copper coils for thermal expansion. The quartz tube is constricted to hold a perforated ceramic disk, size 00 , which supports the silver. The silver is cut from 6-inch-square sheets, 0.001 inch thick, into strips one-eighth inch wide. Loosely folded, 1 gram of the strips is pressed down the quartz tube to form a right cylinder 1 inch long.

The amplifier and power supply are constructed on an aluminum chassis, $3 \times 13 \times 17$ inches, which is attached to a standard 19 -inch faceplate 10 inches high. The instrument controls that are used routinely and the indicating microammeter are mounted on the faceplate. The absorption chamber is constructed from two pieces of $1 / 4$-inch aluminum L-beam, $2 \times 3 \times 18$ inches, joined by a rabbet along one edge of each piece. The two sections slide together and are held firmly by end plates recessed to fit the chamber cross section. Thus two walls of the chamber can be easily removed as a unit and the internal surfaces cleaned without disconnecting the circuitry.

A vaneaxial exhaust fan $(1,300 \mathrm{rpm}, 68 \mathrm{cfm})$ is attached to the ultraviolet-lamp end of the chamber through an adaptor plate. The fan is operated from a 


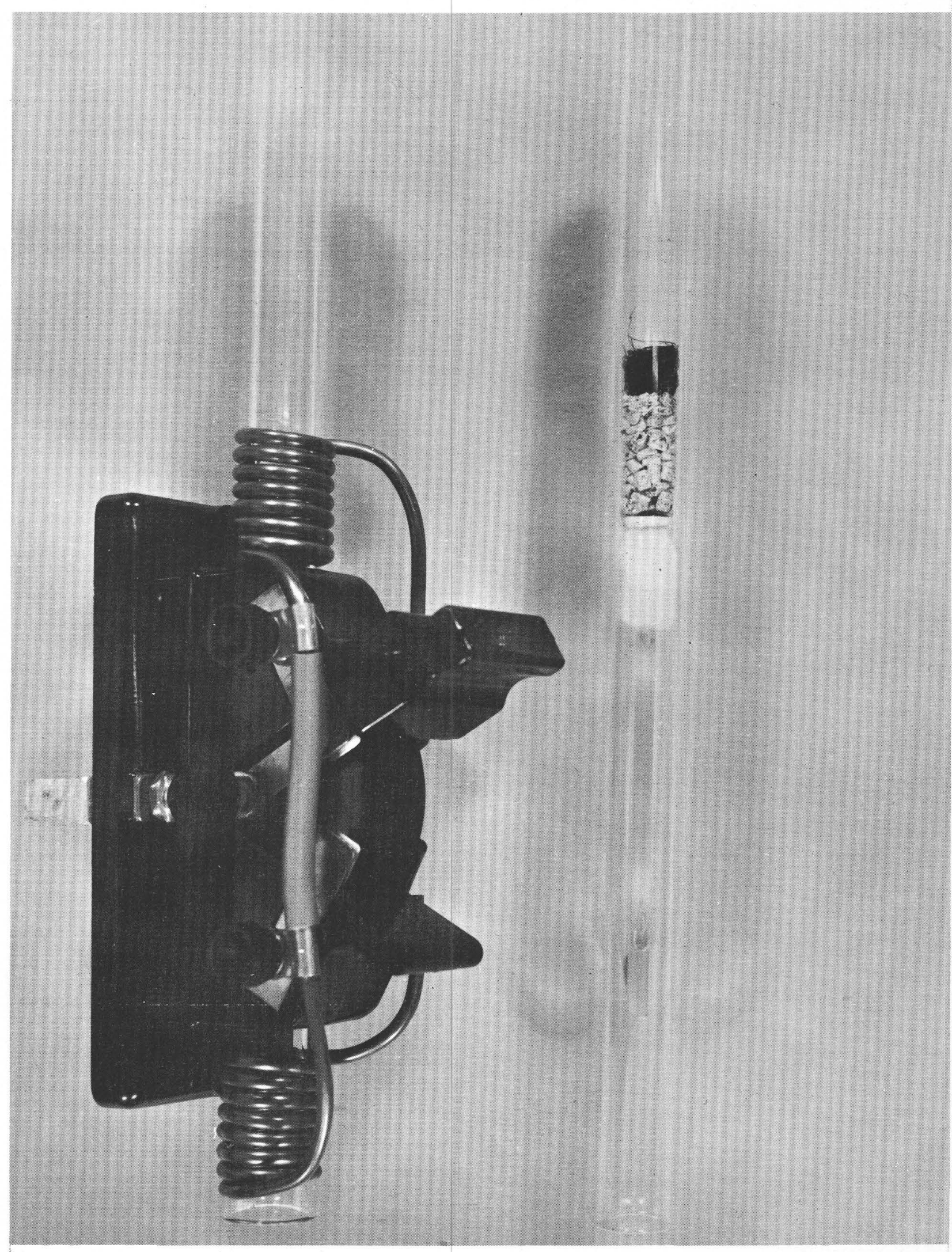

Figure 3.-Amalgamative mercury-extraction stage (thermoamalgamator). 
variac and is positioned so that the interference from ultraviolet-absorbing ozone, which is created continuously by the lamp, will be removed from the light path. The mass and large surface area of the chamber serve as an effective heat sink to keep the ultraviolet lamp at an even temperature and a constant intensity. The octal base of the photocell at the opposite end of the chamber extends about 1 inch through a semipermanent O-ring seal for easy insertion in its receptical on the amplifier chassis. The chamber assembly is attached to the amplifier by a mounting plate and four $/ 4$-inch wing bolts.

Tube fittings are placed at both ends of the chamber and connected to the $T$-valve with plastic tubing. The same tubing is used to connect the output of the amalgamative stage to the $T$-valve.

\section{INSTRUMENT DESIGN (ELECTRONIC)}

The electronic circuitry for the mercury vapor detector consists of a single-photocell balanced bridge and a high-gain twin-triode differential amplifier with both halves of the triode conducting at all times (Westinghouse Electric Corporation, 1948; Valley and Wallman, 1948; fig. 4). The photocell, which is physically in the absorption chamber, is electronically connected as one arm of the bridge circuit. Two series variable resistors $\left(R_{1}\right.$ and $\left.R_{2}\right)$ in the opposite arm are the coarse and fine zero controls for the instrument. The lower arms of the bridge circuit $\left(R_{3}\right.$, $R_{4}$, and $R_{5}$ ) are also the biasing resistors for the amplifier.

A 6201 vacuum tube, a ruggedized ver ion of a 12AT7 with low microphonics, is connected as a differential amplifier. The overall circuit voltare is adjusted by $R_{15}$, a variable bleeder resistior in the voltage divider system of the power supply. The current in the two triodes of the differential amplifier is normalized by adjusting the plate voltage on each tube with a common variable resistor $\left(R_{6}\right)$ : The ad justment of $R_{5}$ in the lower right-hand arm of the bridge allows for the change in sensitivity which is expected when the photocell is replaced or has lost sensitivity owing to natural aging. All the variable circuit parameters are interrelated and must be alternately ac justed to attain optimum instrument performance. A 10 -microampere taut band meter, shunted by the appropriate range resistors, between the plates of the triodes indicates the amplified change in current in the bridge circuit caused by absorption of the ultraviolet light in the chamber.

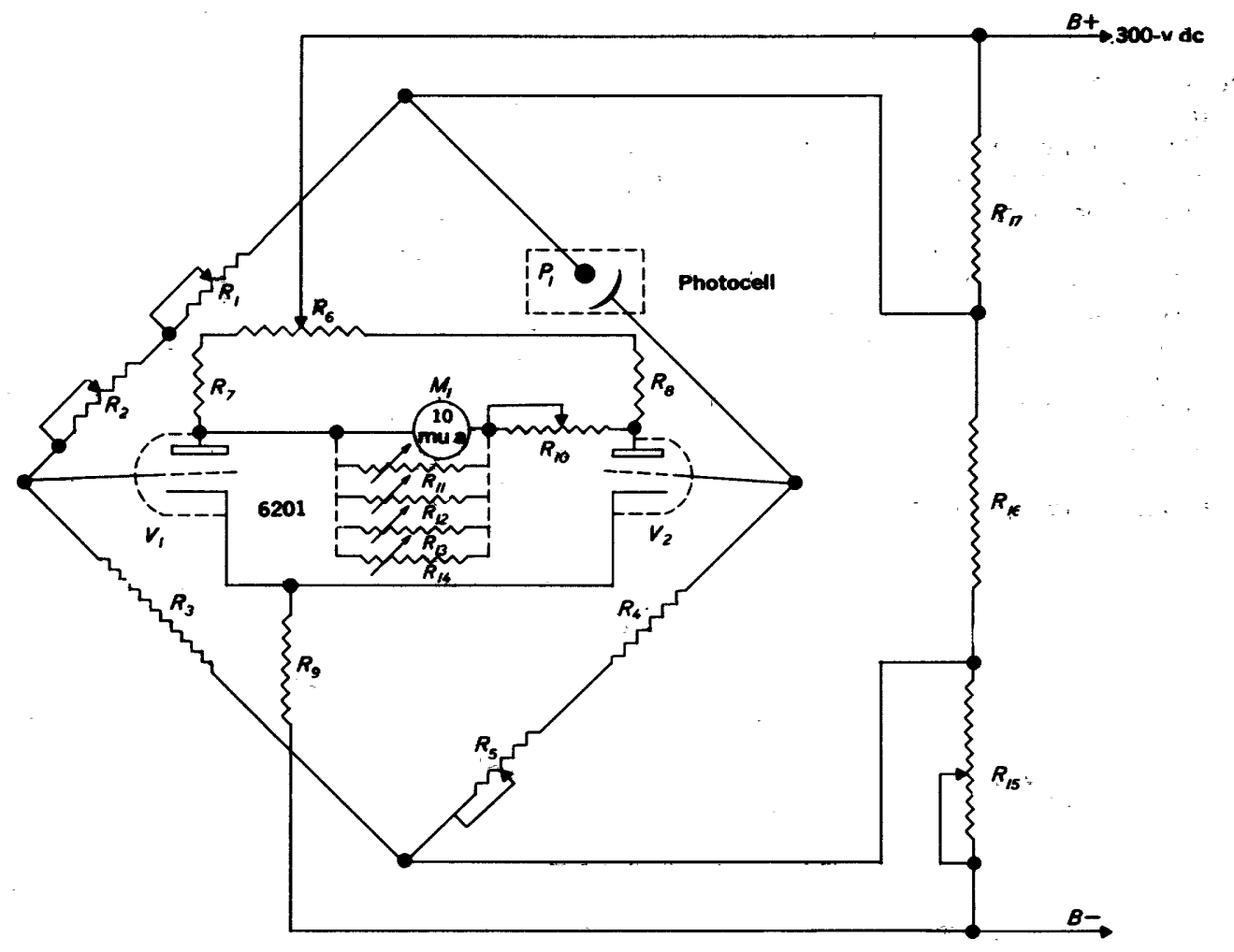

Figure 4.-Circuit diagram of mercury vapor detector. mu a, microamperes. 
In the quiescent state, with no mercury present, the current in the photocell resulting from excitation by the ultraviolet lamp is balanced by adjusting $R_{1}$ and $\mathrm{R}_{2}$; this balance nullifies the circuit. The bias developed from the voltage drop across grid resistors $R_{3}, R_{4}$, and $R_{5}$ controls the current in $V_{1}$ and $V_{2}$; and as there is no difference between the plate potentials, there is no meter indication. In this condition the grid voltage relative to the common cathode for both $V_{1}$ and $V_{2}$ should be slightly negative, -0.2 to -0.4 volt de.

When mercury vapor enters the absorption chamber, strong absorption of the ultraviolet light occurs, and the current in the photocell and the right half of the bridge circuit is sharply reduced. The bias on $\mathrm{V}_{2}$ then becomes more negative while the plate potential increases in a positive direction and causes the meter to deflect to the right. This deflection is proportional to the mercury concentration in the absorption chamber when the instrument is calibrated.

A packaged $300-\mathrm{v}$ dc 50-milliampere solid-state power supply, as well as the supply diagrammed in figure 5 , has been used satisfactorily with the differential amplifier.

The ultraviolet-lamp power supply is a ballasttype transformer available from the lamp manufacturer.

\section{INSTRUMENT OPERATION}

A. Induction heater (radio frequency) and amalgamative stage:

1. Ad just the water flow through radio-frequency coils to trickle (a few drops per second).

2. Turn the on-off switch (green light) on induction heater to on and allow 45 seconds for the instrument to reach ambient temperature. The high-voltage power switch (red light), which provides power (heat) for the sample holder and the silver mercury trap, may now be turned on and operated as desired. (For convenient oper a tion, a foot switch can be substituted for the high-voltage power switch in the instrument.)
3. Set the knife-blade switch, which is on the front of the radio-frequency induction unit, in the neutral position. The switch alternately applies power to the steel sample holder and the silver mercury trap. This action, coordinated with on-off high-voltage power switch, sequentially releases mercury from the rock in the sample holder to the mercury trap, and from the mercury trap into the absorption chamber where the measurement takes place.

B. Amplifier unit:

1. Set the range switch selector to position 5 .

2. Turn the on-off switch to on.

3. Adjust the variac blower control to 45 .

4. Turn the on-off switch on the ultraviolet-lamp power supply to on. (The warmup time for the ultraviolet lamp is approximately 15 minutes.)

5. As the ultraviolet lamp warms up, the emitted light becomes more intense, and the meter needle drifts to the left. The range switch may be turned to progressively lower numbers (greater sensitivity) and the fine zero control adjusted to maintain $\varepsilon n$ approximate zero setting during this warmup period.

C. The instrument response is divided irto five ranges, in order of decreasing sensitivity, with alternate range factors of 5 and 2 .

Note.-Range 2 seems to be the one most used for sample analysis; however, if the sensitivity of this range is too great, a second or third equal measure of the sample may be run on a less sensitive range.

\section{CALIBRATION}

The mercury vapor detector is calibrated with mercury-saturated air, which is obtained b"' placing a few grams of mercury in a 60-milliliter serum bottle having a sleeve-type rubber-membrane stopper. The air is withdrawn from the bottle with a hypodermic syringe by puncturing the membrane to insert the needle. The membrane seals itself hermetically as the needle is removed. Figure 6 is the temperature-seturation curve for mercury vapor in air.

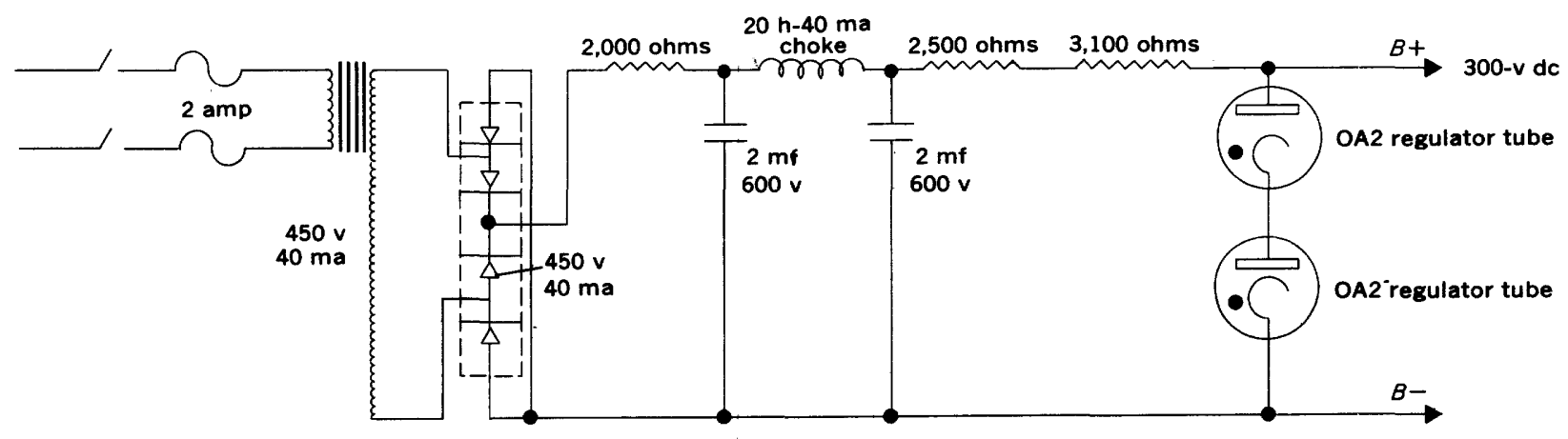

Figure 5.-Circuit diagram of power supply. $h$, henrys; ma, milliamperes; mf, microfarads. 
After the instrument has been adjusted to a stable zero reading, inject a sample of the air from the serum bottle into the lower end of the quartz tube with the hypodermic syringe. Turn on the high-voltage switch on the induction furnace and heat the silver mercury trap for approximately 10 seconds or until a peak meter reading has been observed. In a similar manner, inject different volumes of mercury-saturated air for all ranges of sensitivity until sufficient information has been obtained to prepare calibration curves of nanograms of mercury versus meter readings, in microamperes for each range. The meter reading may be used to numerically quantitize the unknown mercury value derived from a crushed rock sample.

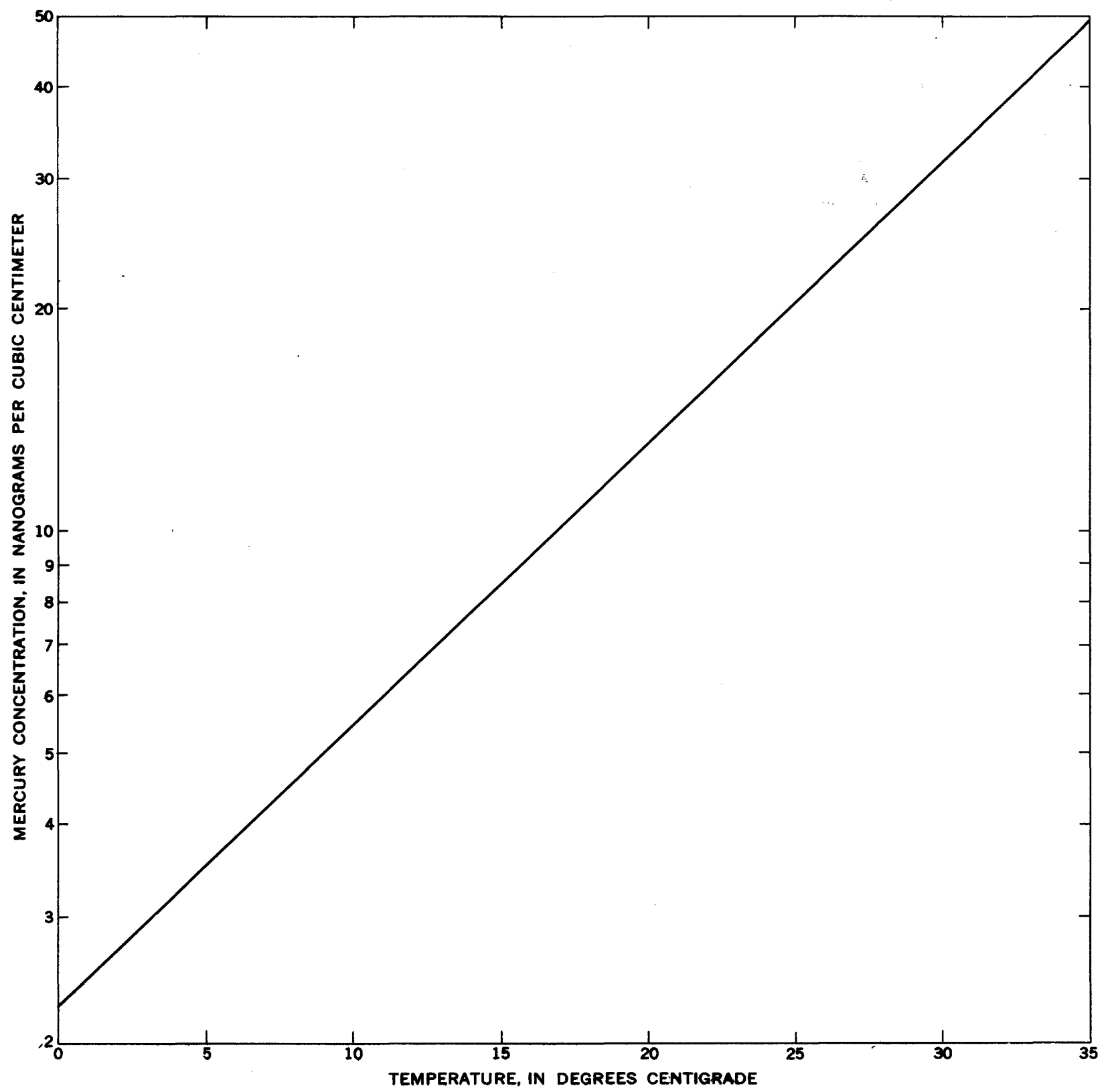

Figure 6.-Temperature-saturation curve for mercury vapor in air. 


\section{REFERENCES}

Erickson, R. L., Marranzino, A. P., Oda, Uteana, and and Janes, W. W., 1964, Geochemical exploration near the Getchell mine, Humboldt County, Nevada: U.S. Geol. Survey Bull. 1198-A, p. A1-A26.

Erickson, R. L., VanSickle, G. H., Nakagawa, H. M., McCarthy, J. H., Jr., and Leong, K. W., 1966, Gold geochemical anomaly in the Cortez district, $\mathrm{Ne}-$ vada: U.S. Geol. Survey Circ. 534, 9 p.

Friedrich, G. H., and Hawkes, H. E., 1966, Mercury as an ore guide in the Pachuca-Real Del Monte district, Hidalgo, Mexico: Econ. Geology, v, 61, no. 4, p. 744753.

Hawkes, H. E., and Williston, S. H., 1962, Mercury vapor as a guide to lead-zinc-silver deposits: Mining Cong. Jour., v. 48, no. 12, p. 30-32.

Saukov, A. A., 1946, Geokhimiya rtuti [The geochemistry of mercury]: Acad. Sci. U.S.S.R., Inst. Geol. Sci., Trans. 78, Mineralog.-Geochem. Ser. 17, $129 \mathrm{p}$.
Valley, G. E., and Wallman, Henry, 1948, Vacuum tube amplifiers: New York, McGraw-Hill Book Co., Inc., $743 \mathrm{p}$.

Vaughn, W. W., and McCarthy, J. H., Jr., 1964, An instrumental technique for the determination of submicrogram concentrations of mer ury in soils, rocks, and gas, in Geological Survey research 1964: U.S. Geol. Survey Prof. Paper 501-D, p. D123-D127.

Westinghouse Electric Corporation, 15.48, Industrial electronics reference book, prepare 1 by electronic engineers of the corporation: New Ycrk, John Wiley \& Sons, Inc., 680 p.

Williston, S. H., 1964, The mercury halc method of exploration: Eng. Mining Jour., v. 16?, no. 5, p. 98101.

Williston, S. H., and Morris, M. H., 1965, Method and apparatus for measurement of mercury vapors: U.S. Patent 3173016. 